\title{
Costs of services for homeless people with mental illness in 5 Canadian cities: a large prospective follow-up study
}

\author{
Eric A. Latimer PhD, Daniel Rabouin MSc, Zhirong Cao MSc, Angela Ly MHA, Guido Powell MSc, \\ Tim Aubry PhD, Jino Distasio PhD, Stephen W. Hwang MD, Julian M. Somers PhD, \\ Vicky Stergiopoulos MD, Scott Veldhuizen PhD, Erica E.M. Moodie PhD, Alain Lesage MD MPhil, \\ Paula N. Goering RN PhD; for the At Home/Chez Soi Investigators
}

\section{Abstract}

Background: Limited evidence on the costs of homelessness in Canada is available. We estimated the average annual costs, in total and by cost category, that homeless people with mental illness engender from the perspective of society. We also identified individual characteristics associated with higher costs.

Methods: As part of the At Home/Chez Soi trial of Housing First for homeless people with mental illness, 990 participants were assigned to the usual-treatment (control) group in 5 Canadian cities (Vancouver, Winnipeg, Toronto, Montréal and Moncton) between October 2009 and June 2011. They were followed for up to 2 years. Questionnaires ascertained service use and income, and cityspecific unit costs were estimated. We adjusted costs for site differences in sample characteristics. We used generalized linear models to identify individual-level characteristics associated with higher costs.

Results: Usable data were available for 937 participants (94.6\%). Average annual costs (excluding medications) per person in Vancouver, Winnipeg, Toronto, Montréal and Moncton were \$53 144 (95\% confidence interval [Cl] \$46 297-\$60 095), \$45 565 (95\% Cl \$41 039-\$50 412), \$58 972 (95\% Cl \$52 237-\$66 085), \$56 406 (95\% Cl \$50 654-\$62 456) and \$29 610 (95\% Cl $\$ 24$ 995-\$34 480), respectively. Net costs ranged from $\$ 15530$ to $\$ 341535$. Distributions of costs across categories varied significantly across cities. Lower functioning and a history of psychiatric hospital stays were the most important predictors of higher costs.

Interpretation: Homeless people with mental illness generate very high costs for society. Programs are needed to reorient this spending toward more effectively preventing homelessness and toward meeting the health, housing and social service needs of homeless people.

\begin{abstract}
A n estimated 35000 Canadians are homeless on any given night, and over 235000 experience homelessness over the course of a year. ${ }^{1}$ In some jurisdictions, the discussion has shifted toward how homelessness can be ended rather than on how to manage it. ${ }^{1,2}$ Ending homelessness will require resources in the form of targeted prevention interventions, ${ }^{2}$ development of affordable housing and a variety of housing and support programs such as Housing First, in which homeless people are offered immediate access to permanent housing together with long-term, individualized support. ${ }^{3}$ Arguments for additional government expenditures on programs to end homelessness can be better framed if the costs of maintaining the status quo are
\end{abstract}

well understood. To this end, estimates of the costs of homelessness are needed.

Limited information is available on the economic costs that homeless people engender in Canada. Based on a sample of 10 people, in 1998-1999, service and shelter costs of

Competing interests: None declared.

This article has been peer reviewed.

Correspondence to: Eric Latimer, eric.latimer@mcgill.ca

CMAJ Open 2017. DOI:10.9778/cmajo.20170018 
homeless people were estimated to range on average from $\$ 30000$ to $\$ 40000$ per person in British Columbia. ${ }^{4}$ Relying on these estimates and combining them with data from a variety of other sources, a subsequent report from that province placed the cost of health, social and justice services at over \$55 000 in 2006 dollars (over \$63000 in 2016 dollars) per year for people who are absolutely homeless. ${ }^{5}$ In a study based on 2006-2007 data conducted in Calgary, a different approach was used: an estimate of total costs engendered by homeless people was divided by a weighted sum of numbers of transiently and chronically homeless people. ${ }^{6}$ That study showed substantially higher costs: $\$ 72444$ per person per year for transiently homeless people to $\$ 134642$ per year for chronically homeless people (about \$87000 and \$161 000 in 2016 dollars, respectively $\left.{ }^{7}\right)$.

The present study draws from the Canadian At Home/ Chez Soi study, a multisite randomized controlled trial of Housing First that assembled a large sample of people with mental illness who were absolutely homeless at the time of recruitment or were precariously housed and had a recent history of absolute homelessness. ${ }^{8-10}$ Using data for participants assigned to the control group, who were receiving usual services in their city, we aimed to estimate the average annual net cost of resources spent per person on homeless people with mental illness, by city and by cost category, and to identify individual characteristics that predict higher costs.

\section{Methods}

The pan-Canadian At Home/Chez Soi project used a randomized trial design to test the Housing First approach in 5 Canadian cities: Vancouver, Winnipeg, Toronto, Montréal and Moncton. ${ }^{8-10}$ Between October 2009 and June 2011, 2148 homeless people with mental illness were randomly allocated to the main trial. They were followed for up to 2 years in a standardized manner until Mar. 31, 2013. Of the 2148 people, 1158 were randomly assigned to the Housing First intervention (experimental group), and 990 to treatment as usual (control group). ${ }^{11}$ Using questionnaires administered at regular intervals, the investigators collected comprehensive psychometric and resource use data over a 2-year period. The current report uses data for the 937 participants $(94.6 \%$ of the original sample) who received usual treatment and for whom we had usable data.

\section{Sample}

To be included in the study, people needed to be of legal adult status, be absolutely homeless or precariously housed, and have a serious mental disorder, with or without a coexisting substance use disorder. ${ }^{8}$ People who were currently receiving services from another Assertive Community Treatment or Intensive Case Management team were excluded, as were those who did not have legal status in Canada and thus were not eligible for government benefits.

Participants were recruited through a combination of methods, including referrals from shelters, hospital emer- gency departments and other service providers, outreach in shelters and other locations where homeless people were known to be found and self-referral. Legal adult status meant being 18 years or older except in Vancouver, where the threshold age was 19. Participants needed to be absolutely homeless or precariously housed at the time of the screening interview. Absolute homelessness was defined as having had no fixed place to stay for more than 7 nights with little likelihood of obtaining accommodation in the upcoming month or being discharged from an institution, prison, jail or hospital with no fixed address. Being precariously housed was defined as having a single-room-occupancy building, rooming house or hotel/motel as one's primary residence together with having had 2 or more episodes of being absolutely homeless (as defined in this study) in the previous year. Study participants also needed to have 1 or more of 6 mental disorders: major depression, manic or hypomanic episode, posttraumatic stress disorder, mood disorder with psychotic features or current psychotic disorder, with or without concurrent substance use disorder, as determined by Diagnostic and Statistical Manual of Mental Disorders, fourth edition criteria on the Mini International Neuropsychiatric Interview at the time of entry. In cases in which there was ambiguity, additional evidence was obtained, with the participant's consent, from his or her medical record.

The overall sample size of the At Home/Chez Soi study was calculated so that each site would be able to detect an effect size of 0.5 between the experimental and control groups for the major outcome variables, with an $\alpha$ of 0.05 and a $\beta$ of 0.20 . This was estimated to require 63 participants per treatment group, or, assuming $40 \%$ attrition, an initial sample size of about 100 per group.

Figure 1 shows how the final sample of 937 participants for whom we had usable data was obtained. Twenty-nine participants in the usual-treatment group were identified as having died during the follow-up period. Of the 29, 20 had at least 1 completed Health, Social and Justice Service Use Inventory and 1 Residential Time-Line Follow-Back Inventory. The data for these 20 people were included in the analysis. However, their imputed average costs were down-weighted in computing average costs in proportion to the time from baseline until their death.

\section{Measures}

Demographic variables were collected at baseline, and several measures of physical and mental health status, functioning, quality of life and other domains were collected at baseline and at 6-month intervals over the follow-up period. The 6-month questionnaires included the Multnomah Community Ability Scale (MCAS), ${ }^{12,13}$ a well-validated measure of functioning, which was completed by the interviewer at the conclusion of the interview on the basis of his or her observations and the interview responses provided by the participant. All other study data were self-reported.

Three additional instruments were used to capture resource use and income. The Health, Social and Justice Service Use Inventory, developed for the At Home/Chez 


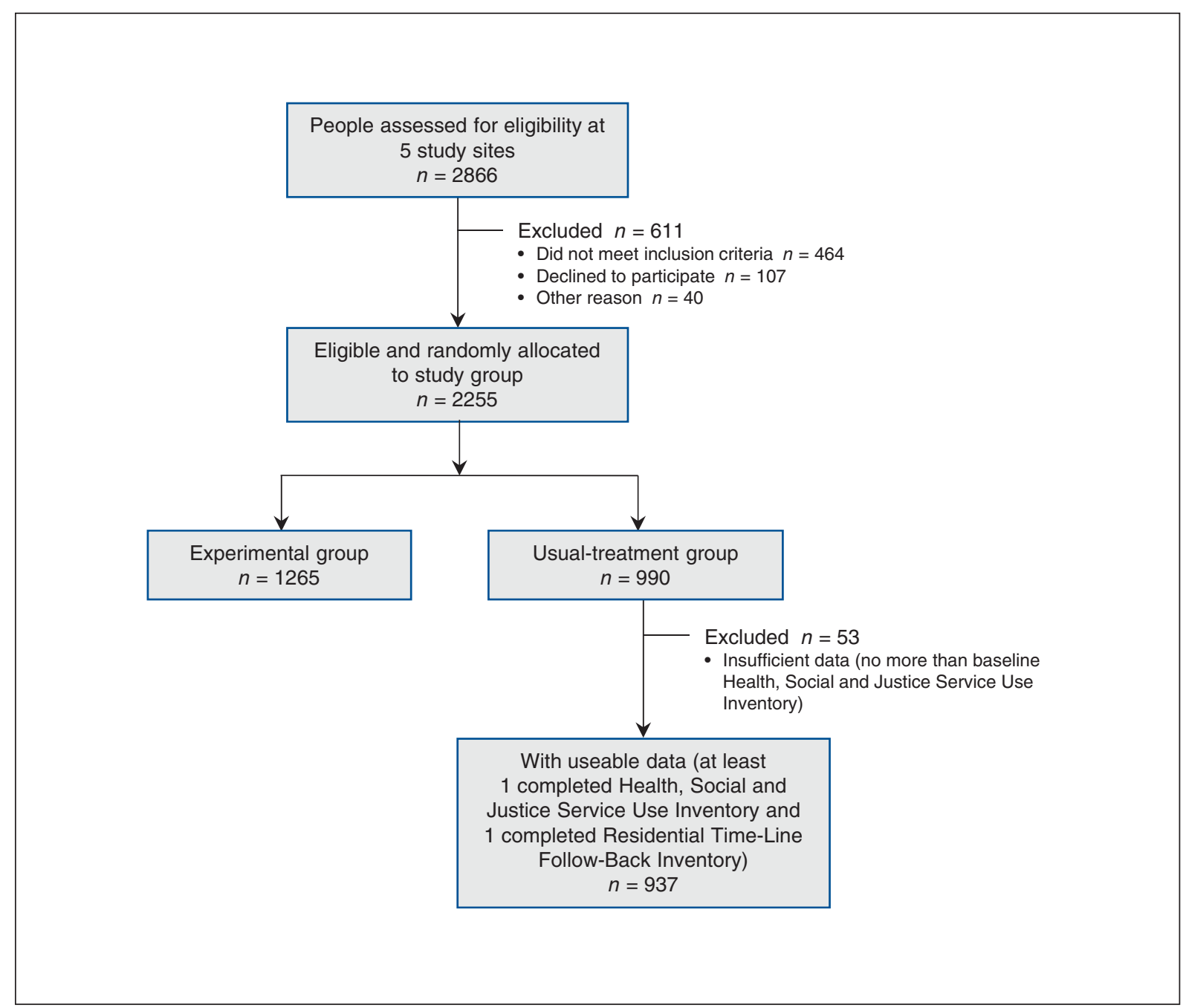

Figure 1: Flow chart showing selection of study participants.

Soi study, elicited information about the participant's use of all nonovernight health- and justice-related services that had occurred in the previous 30 days during visits to or by health and social service providers outside hospitals, or in the past 6 months for other events judged to be of high saliency (e.g., emergency department visits, arrests) or likely to have occurred regularly (e.g., visits to drop-in centres). The Residential Time-Line Follow-Back Inventory, ${ }^{14}$ administered at 3-month intervals, asked participants to reconstruct where they were staying every night since the previous interview. It was adapted to each city in our study from an instrument originally developed for New York City. With a view to being able to assign costs to service use, the inventory recorded simultaneous places of residence; for example, if a participant had an apartment and had a hospital stay, both places were recorded. The Vocational Time-Line Followback questionnaire, based on an instrument developed for another study ${ }^{15}$ and also administered at 3 -month intervals, asked about income (both legal and illegal) received month by month, by source, and any regular or casual work obtained during the previous 3 months and the 3 months before baseline. It also elicited information about contacts with the police and involvement with the criminal justice system. Owing to the length of the baseline interview, the Residential Time-Line Follow-Back Inventory and Vocational Time-Line Follow-Back questionnaire were administered for the first time at the 3 -month interview, with the latter asking also about the 3 months before baseline. The validity of these 3 instruments has been partially established from a comparison with administrative data at the Vancouver site. ${ }^{16}$

The longer interviews conducted every 6 months and the final interview were carried out in person, and the shorter interviews at 3,9,15 and 21 months (except in cases in which the 21 -month interview was the final interview) were normally carried out by telephone.

Most participants (84\%) were followed for 24 months. Follow-up was reduced to 21 months for a minority (16\%) of participants for budgetary reasons unrelated to participant characteristics. ${ }^{11}$ 
Our questionnaires did not cover the use or cost of medications because of the difficulty of obtaining reliable information on them as well as owing to respondent burden. Furthermore, restrictions on sharing administrative data across Canadian provinces prevented us from combining information on cost of medications at the participant level from administrative databases across provinces. We did, however, have access to data on filled prescriptions (for all types of prescription drugs) for almost all Montréal site participants, from the Quebec Health Insurance Board. Thus we were able to calculate the cost of medications over the 2-year follow-up period for participants at that site. We used this information to calculate a more comprehensive estimate of the total costs engendered by homeless people, including an estimate of the cost of medications.

\section{Procedure}

Participants consented to participate in the study following the screening interviews. Screening and baseline interview data were entered directly into an online database. Once the interview was completed, immediately before randomization, a computerized algorithm classified all participants as high need or moderate need based on data entered during the screening and baseline interviews. To be classified as high need, participants had to have an MCAS score of 62 or less and a current diagnosis of psychotic disorder or bipolar disorder, as assessed with the Mini International Neuropsychiatric Interview, or have been observed as having a psychotic disorder during the screening, and at least 1 of a psychiatric hospital stay(s), comorbid substance use or legal involvement. ${ }^{8}$ At all sites except Moncton, high-need participants were randomly allocated to Housing First with Assertive Community Treatment or usual treatment, and moderate-need participants to Housing First with Intensive Case Management or usual treatment. At the Moncton site, owing to the smaller number of participants, all participants randomly allocated to the experimental arm received Assertive Community Treatment. An adaptive randomization algorithm was used to carry out randomization.

Follow-up methods included 1) requesting, at baseline, the names, telephone numbers and/or addresses of contacts on whom the interviewer team might rely to help locate participants at future interview time points, 2) providing participants with a toll-free number to call once a month to keep in touch with the interviewer team, in exchange for a $\$ 5$ payment, 3) where possible, and with the participant's consent, ensuring that the social assistance office update the interviewer team as to any change in address and 4) in some cities more than others, maintaining a presence in shelters and other locations where homeless people tended to congregate.

Further details on the study methods and instruments used are provided elsewhere. ${ }^{8}$

\section{Perspective of the economic analysis}

We collected and analyzed cost elements from a modified societal perspective. Conventionally, transfer payments such as social assistance and disability benefits are ignored, based on the reasoning that in and of themselves they imply no actual use of resources (apart from any administrative expenses involved in effecting the transfers ${ }^{17}$ In the present analysis, however, following Weisbrod and colleagues, ${ }^{18}$ we included social assistance and disability benefits as costs. The greater part of these payments is used for the subsistence of homeless people, only a small minority of whom are employed. To a large extent, these payments can be viewed as representing simply a different form of support from shelters, food banks and other such services. The inclusion of social assistance and disability benefits as costs, as long as out-of-pocket payments made by participants for food or shelter are excluded to avoid double-counting, may also be viewed as consistent with a social cost-impact analysis. ${ }^{19-21}$

\section{Estimation of unit costs}

We estimated average costs of the various kinds of services that participants reported having received. We originally calculated unit costs in 2011 Canadian dollars but then inflated them to 2016 dollars using the city-specific all-item Consumer Price Index. ${ }^{7}$ Whenever possible, we used a "topdown" approach, i.e., we used financial statements and activity reports to determine the average cost of a service, employing direct allocation to allocate overhead costs. ${ }^{17} \mathrm{We}$ also loaded onto the unit costs a component to represent the opportunity cost of land and buildings. ${ }^{22}$ Using data compiled by the Canadian Institute for Health Information, we added typical physician fees to the costs of hospital stays as well as outpatient and emergency department visits. We also used the Canadian Institute for Health Information data to estimate the costs of physician services provided in physicians' offices. We applied an adjustment to hospital per diems to account for the fact that our population is homeless. ${ }^{23}$ As differences in unit costs could reflect not simply differences in wage levels but also differences in resource intensity that could influence outcomes, we estimated separate unit costs for each site. We calculated many unit costs at a high level of specificity, distinguishing for example in some cases among different single-room-occupancy providers, unit costs for which can vary considerably depending on the amount of support staff present. This could be done in many cases as interviewers usually recorded place names. Owing to resource constraints, in the cases of some unit costs for lowcost (e.g., 911 calls) or low-frequency (e.g., court appearances) services, we extrapolated unit costs estimated at 1 site (usually Montréal) to other sites. ${ }^{9}$

We subtracted from the costs attributed to each participant both casual and regular employment income. Reported income from illegal activities (e.g., sex work, drug dealing) was marginal on average, ${ }^{24}$ and we did not take it into account in our analysis. However, we included income from undeclared casual work, including busking. We treated income from panhandling and gifts from family members in the same way as income from welfare or disability benefits. Loans from family members were assumed to be eventually repaid and were ignored. 


\section{Statistical analysis}

At the Montréal site only, for experimental group participants, it was possible to compare self-reported frequencies of visits by and to Housing First clinical team providers as well as visit duration (recorded with a specific code) with the program's data. This comparison matched the time periods over which the visits were reported by participants, month by month. We calculated, by need level, for home and office visits separately, and separately for number of visits and duration of visits, the average derived from a detailed analysis of administrative data, divided by the average obtained from selfreports. This revealed a strong tendency to underreport number of visits and visit duration, with factors ranging from 0.93 (in this 1 instance, indicating overreporting) to 3.37 , depending on need level, whether the reporting was of number of visits or visit duration, and whether home or office visits were involved. We adjusted frequencies of visits or duration of visits of analogous community-based support providers, for usual-treatment participants, using the corresponding multiplicative factor to account for misreporting. This was done for all sites. No adjustment was made to other frequencies or durations as we did not have comparable data on which to base such adjustments. All subsequent analyses relied on service-use levels, and hence costs, adjusted in this manner.

We described and plotted the distribution of total annualized costs per person, after multiple imputation to address missing data (see below), using a histogram.

As the relative numbers of high-need and moderate-need participants varied by site, and as preliminary analyses had shown an association between need level and costs, we calculated weighted annualized costs per participant by site, with the weights calculated to equalize the proportions of highneed and moderate-need participants across sites. We used as the common proportion the average proportion of high-need participants across all sites (0.43). All results involving costs incorporate this weighting.

For each site, we subdivided costs into 12 categories: supportive housing (housing in which support staff are located within the building; also included [notably for Toronto] subsidized rooms in buildings without on-site support staff), substance use treatment, ambulatory visits, emergency department visits and ambulance, hospital admission for physical cause, hospital admission for psychiatric cause, other (e.g., help lines, day centres), police and court appearances, incarcerations, social assistance/disability benefits and income earned. Owing to the skewed nature of cost data and the presence of some missing data, we used bootstrapping (with 500 replications) followed by multiple imputation with chained equations ${ }^{25,26}$ (20 imputations) to estimate means and $95 \%$ confidence intervals (CIs).

Combining data from all sites, we used generalized linear models ${ }^{27}$ to regress total costs and costs of the 3 most costly categories against a set of demographic, clinical and baseline service-use predictors selected a priori. These variables included 1) those that contributed to the algorithm used to classify participants as high need or moderate need, 2) age, sex and longest period of homelessness as a measure of chronicity of homelessness (variables that previous research suggested are associated with costs engendered by homeless people ${ }^{28,29}$ ) and 3 ) site, which seemed likely to be associated in a systematic way with costs. We estimated both unadjusted and adjusted associations. We used bootstrapping and multiple imputation to calculate effect estimates and $95 \%$ CIs.

A comparison using the Akaike information criterion, of $\log$ link and identity link functions, and $\gamma$ and Gaussian distributions led to the choice of the log link and the $\gamma$ distribution. These were also supported by the Pregibon link test and, for the distribution family, the modified Park test. ${ }^{27,30,31}$

\section{Ethics approval}

Ethics approval was obtained from the local ethics review board at each data collection site and from the universityaffiliated teaching hospital (Centre for Addiction and Mental Health) where the coordinating centre was based. ${ }^{8}$

\section{Results}

Table 1 shows the participants' characteristics at baseline. They had a mean age of 41.03 (standard deviation 11.32 ) years, and about two-thirds (69.6\%) were men. About three-quarters (76.6\%) had a psychotic or bipolar disorder, and roughly half $(53.6 \%)$ had a history of alcohol or illicit substance abuse or dependence. A total of $38.8 \%$ had had 2 or more hospital stays in 1 of the previous 5 years, and slightly more than a third $(36.3 \%)$ had been arrested in the previous 6 months. On average, the longest single period of homelessness participants had experienced was 2.5 years. Sample characteristics were roughly similar across sites, with the most notable difference being that the rate of alcohol use or dependence was far higher in Winnipeg than at other sites: $67.9 \%$ versus $33.2 \%-44.9 \%$.

A complete set of unit costs with their sources is presented in Appendix 1, available at www.cmajopen.ca/content/5/3/ E576/suppl/DC1.

Unadjusted total costs per person per year are shown in Figure 2. The distribution is heavily skewed to the right, with a median of $\$ 39640$ and a mean of $\$ 50$ 810. The 25th and 75th percentiles are $\$ 27030$ and $\$ 59860$, respectively; the 90th percentile is $\$ 93165$. The minimum is $-\$ 15530$ and the maximum $\$ 341535$. Seven people who consumed very few health, social or justice services but earned substantial income had negative costs.

Table 2 shows adjusted average annualized costs by category and by site. Total costs were similar across the 3 largest cities (Toronto, Montréal and Vancouver), lower in Winnipeg and significantly lower in Moncton. Some notable differences emerged in the distributions of costs by category across sites. In Toronto, costs for ambulatory visits were higher than in Montréal or Vancouver, and costs for hospital stays (for both physical and psychiatric causes) were lower. Costs for police and court appearances were much higher in Toronto than in Montréal or Vancouver. Costs for substance use treatment were lower in Toronto than in Montréal or Vancouver. Finally, costs for supportive housing were especially high in Montréal, nearly double those in the city with the next highest costs, Winnipeg. 
Table 1: Baseline characteristics of homeless participants with mental illness who were receiving usual services, by study site

\begin{tabular}{|c|c|c|c|c|c|c|}
\hline \multirow[b]{2}{*}{ Characteristic } & \multicolumn{6}{|c|}{ Site; no. (\%) of participants ${ }^{*} \dagger$} \\
\hline & $\begin{array}{l}\text { Moncton } \\
n=96\end{array}$ & $\begin{array}{l}\text { Montréal } \\
n=183\end{array}$ & $\begin{array}{l}\text { Toronto } \\
n=247\end{array}$ & $\begin{array}{l}\text { Winnipeg } \\
n=218\end{array}$ & $\begin{array}{l}\text { Vancouver } \\
n=193\end{array}$ & $\begin{array}{c}\text { Total } \\
n=937 \ddagger\end{array}$ \\
\hline Male & $61(63.5)$ & $135(73.8)$ & $183(74.09)$ & $136(62.39)$ & $137(70.98)$ & $652(69.58)$ \\
\hline $\begin{array}{l}\text { Psychotic disorder or bipolar } \\
\text { disorder }\end{array}$ & $57(59.4)$ & $119(65.0)$ & $196(79.35)$ & $179(82.11)$ & $167(86.53)$ & $718(76.63)$ \\
\hline $\begin{array}{l}\text { Alcohol dependence or } \\
\text { abuse }\end{array}$ & $38(39.6)$ & $62(33.9)$ & $111(44.94)$ & $148(67.89)$ & $64(33.16)$ & $423(45.14)$ \\
\hline $\begin{array}{l}\text { Illicit substance dependence } \\
\text { or abuse }\end{array}$ & $59(61.5)$ & $101(55.2)$ & $113(45.75)$ & $112(51.38)$ & $117(60.62)$ & $502(53.58)$ \\
\hline $\begin{array}{l}\geq 2 \text { hospital stays for } \\
\text { psychiatric cause within a } \\
\text { year in previous } 5 \mathrm{yr}\end{array}$ & $30(31.6)$ & $80(44.9)$ & $106(43.44)$ & $54(25.00)$ & $94(50.81)$ & $364(39.65)$ \\
\hline Arrested in previous 6 mo & $34(35.8)$ & $61(33.7)$ & 91 (36.99) & $72(33.03)$ & $82(43.16)$ & $340(36.56)$ \\
\hline High-needs group & $42(43.8 \S)$ & $81(44.3)$ & $88(35.63)$ & $92(42.20)$ & $97(50.26)$ & $400(42.69)$ \\
\hline Age, mean $\pm S D, y r$ & $40.38 \pm 10.77$ & $43.53 \pm 10.24$ & $41.47 \pm 12.12$ & $38.59 \pm 11.35$ & $41.02 \pm 11.01$ & $41.03 \pm 11.32$ \\
\hline $\begin{array}{l}\text { Longest single period of } \\
\text { homelessness, mean } \pm \mathrm{SD} \text {, } \\
\text { mo }\end{array}$ & $18.69 \pm 26.69$ & $29.41 \pm 37.43$ & $36.74 \pm 55.09$ & $27.90 \pm 37.86$ & $29.75 \pm 38.01$ & $30.01 \pm 42.48$ \\
\hline MCAS score, mean \pm SDף & $59.07 \pm 8.08$ & $59.58 \pm 9.38$ & $61.57 \pm 7.05$ & $60.95 \pm 7.72$ & $57.28 \pm 9.76$ & $59.89 \pm 8.52$ \\
\hline \multicolumn{7}{|c|}{$\begin{array}{l}\text { Note: MCAS = Multnomah Community Ability Scale, SD = standard deviation. } \\
\text { *Except where noted otherwise. } \\
\text { tThe numbers of participants who were assigned to the usual-treatment group, by site, were } 100,184,274,232 \text { and } 200 \text {, respectively. } \\
\text { fData were missing for additional participants for } 3 \text { variables: } 2 \text { or more hospital stays in } 1 \text { of the previous } 5 \text { years }(n=918) \text {, arrested in previous } 6 \text { months ( } n=930) \text { and } \\
\text { longest single period of homelessness }(n=916) \text {. } \\
\text { §Calculated retrospectively with the use of the same algorithm as at the other sites. } \\
\text { qA higher score indicates higher functioning. }\end{array}$} \\
\hline
\end{tabular}

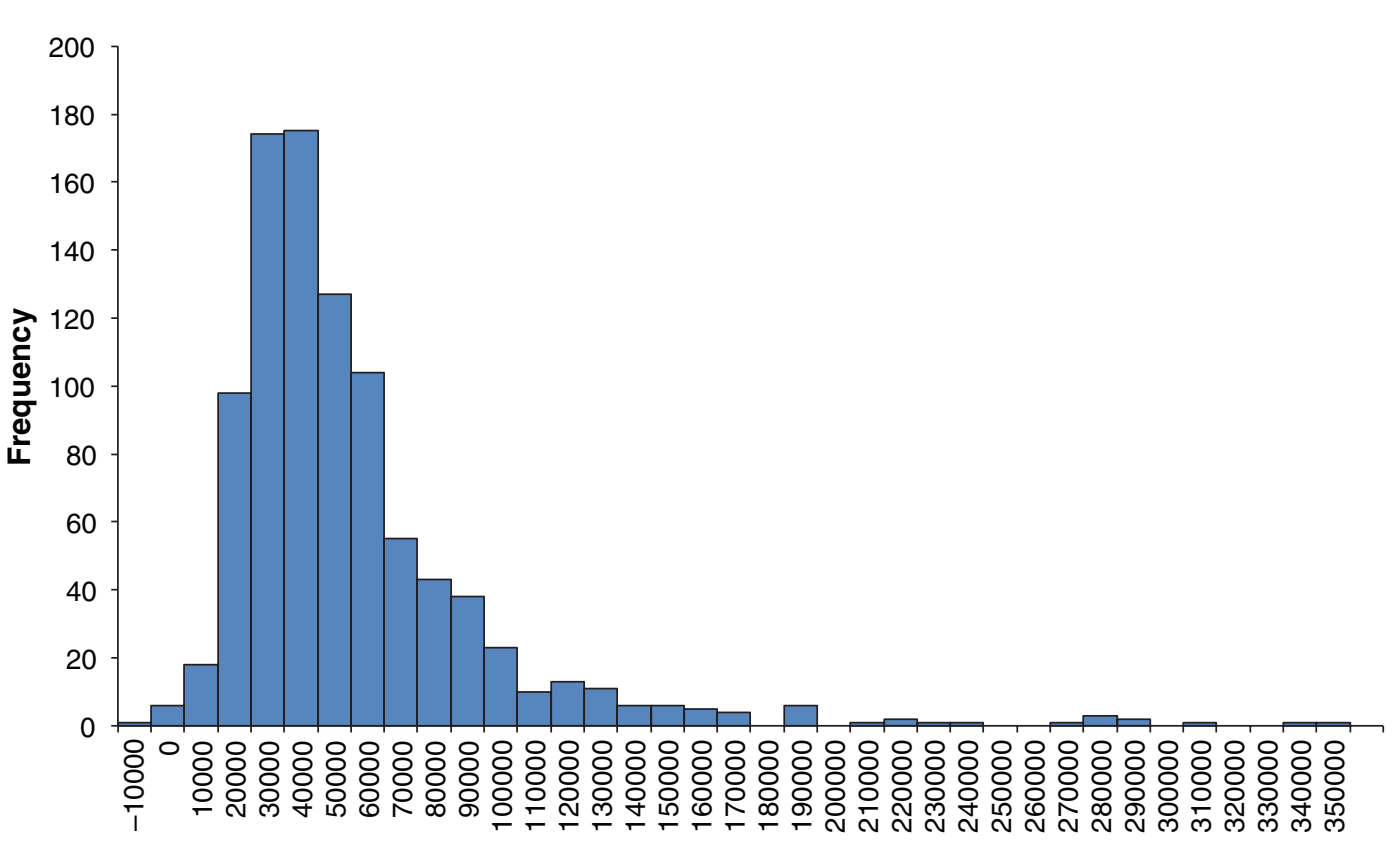

Annual cost, $\$$

Figure 2: Distribution of total annualized costs per person across the sample (subtracting earned income from costs associated with use of health, social and justice services, including social assistance and disability benefits). 


\begin{tabular}{|c|c|c|c|c|c|}
\hline \multirow[b]{2}{*}{ Cost element } & \multicolumn{5}{|c|}{ Site; weighted mean cost $(95 \% \mathrm{Cl}), \$^{*}$} \\
\hline & Moncton & Montréal & Toronto & Winnipeg & Vancouver \\
\hline Shelters & $\begin{array}{c}2240 \\
(1171-3526)\end{array}$ & $\begin{array}{c}4244 \\
(3405-5249)\end{array}$ & $\begin{array}{c}6411 \\
(5411-7219)\end{array}$ & $\begin{array}{c}1091 \\
(827-1364)\end{array}$ & $\begin{array}{c}4279 \\
(3328-5461)\end{array}$ \\
\hline Supportive housing $†$ & $\begin{array}{c}776 \\
(407-1392)\end{array}$ & $\begin{array}{c}5879 \\
(4450-7523)\end{array}$ & $\begin{array}{c}1628 \\
(1077-2308)\end{array}$ & $\begin{array}{c}3271 \\
(2575-4208)\end{array}$ & $\begin{array}{c}2335 \\
(1476-3327)\end{array}$ \\
\hline Substance use treatment & $\begin{array}{c}632 \\
(336-1003)\end{array}$ & $\begin{array}{c}2098 \\
(1289-3046)\end{array}$ & $\begin{array}{c}1012 \\
(577-1629)\end{array}$ & $\begin{array}{c}2313 \\
(1580-3049)\end{array}$ & $\begin{array}{c}2651 \\
(1684-3710)\end{array}$ \\
\hline Ambulatory visits & $\begin{array}{c}5642 \\
(3976-7307)\end{array}$ & $\begin{array}{c}5621 \\
(4523-6720)\end{array}$ & $\begin{array}{c}12545 \\
(9895-15194)\end{array}$ & $\begin{array}{c}9019 \\
(7324-10714)\end{array}$ & $\begin{array}{c}7343 \\
(5555-9131)\end{array}$ \\
\hline $\begin{array}{l}\text { Emergency department visits } \\
\text { and ambulance }\end{array}$ & $\begin{array}{c}1148 \\
(938-1385) \\
\end{array}$ & $\begin{array}{c}1483 \\
(1094-1896) \\
\end{array}$ & $\begin{array}{c}1699 \\
(1118-2392) \\
\end{array}$ & $\begin{array}{c}2638 \\
(2009-3364) \\
\end{array}$ & $\begin{array}{c}1680 \\
(1244-2134) \\
\end{array}$ \\
\hline $\begin{array}{l}\text { Hospital stay for physical } \\
\text { cause }\end{array}$ & $\begin{array}{c}2762 \\
(745-5699)\end{array}$ & $\begin{array}{c}4666 \\
(2444-7688)\end{array}$ & $\begin{array}{c}1104 \\
(502-1821)\end{array}$ & $\begin{array}{c}3971 \\
(2262-6355)\end{array}$ & $\begin{array}{c}2879 \\
(1089-4481)\end{array}$ \\
\hline $\begin{array}{l}\text { Hospital stay for psychiatric } \\
\text { cause }\end{array}$ & $\begin{array}{c}2718 \\
(1215-4431)\end{array}$ & $\begin{array}{c}9416 \\
(6095-14042)\end{array}$ & $\begin{array}{c}7475 \\
(3643-12439)\end{array}$ & $\begin{array}{c}4062 \\
(1773-7678)\end{array}$ & $\begin{array}{c}11308 \\
(6090-17462)\end{array}$ \\
\hline $\begin{array}{l}\text { Other (e.g., help lines, day } \\
\text { centres) }\end{array}$ & $\begin{array}{c}1422 \\
(1079-1860)\end{array}$ & $\begin{array}{c}3318 \\
(2702-3898)\end{array}$ & $\begin{array}{c}2652 \\
(2187-3144)\end{array}$ & $\begin{array}{c}2768 \\
(2404-3156)\end{array}$ & $\begin{array}{c}3107 \\
(2670-3605)\end{array}$ \\
\hline Police, court appearances & $\begin{array}{c}4523 \\
(3491-5556) \\
\end{array}$ & $\begin{array}{c}6613 \\
(5283-8192) \\
\end{array}$ & $\begin{array}{c}12393 \\
(9636-15323) \\
\end{array}$ & $\begin{array}{c}5471 \\
(4524-6522) \\
\end{array}$ & $\begin{array}{c}4807 \\
(3587-6396)\end{array}$ \\
\hline Incarceration & $\begin{array}{c}2355 \\
(1117-3733)\end{array}$ & $\begin{array}{c}3464 \\
(1784-5701)\end{array}$ & $\begin{array}{c}2547 \\
(1575-3719)\end{array}$ & $\begin{array}{c}5392 \\
(3685-6950)\end{array}$ & $\begin{array}{c}3125 \\
(1475-5071)\end{array}$ \\
\hline $\begin{array}{l}\text { Social assistance/disability } \\
\text { benefits }\end{array}$ & $\begin{array}{c}6958 \\
(6343-7602)\end{array}$ & $\begin{array}{c}10407 \\
(9906-10849)\end{array}$ & $\begin{array}{c}10265 \\
(9646-11119)\end{array}$ & $\begin{array}{c}6995 \\
(6533-7523)\end{array}$ & $\begin{array}{c}10887 \\
(10341-11497)\end{array}$ \\
\hline Earned income & $\begin{array}{c}1566 \\
(955-2241)\end{array}$ & $\begin{array}{c}804 \\
(519-1099)\end{array}$ & $\begin{array}{c}759 \\
(487-987)\end{array}$ & $\begin{array}{c}1426 \\
(970-1972)\end{array}$ & $\begin{array}{c}1258 \\
(775-1864)\end{array}$ \\
\hline Total & $\begin{array}{c}29610 \\
(24995-34480)\end{array}$ & $\begin{array}{c}56406 \\
(50654-62456)\end{array}$ & $\begin{array}{c}58972 \\
(52237-66085)\end{array}$ & $\begin{array}{c}45565 \\
(41039-50412)\end{array}$ & $\begin{array}{c}53144 \\
(46297-60095)\end{array}$ \\
\hline \multicolumn{6}{|c|}{$\begin{array}{l}\text { Note: } \mathrm{Cl}=\text { confidence interval. } \\
\text { *We obtained } 95 \% \text { Cls by bootstrapping. We carried out } 20 \text { imputations on each of } 500 \text { bootstrap replicates. There were } 301 \text { cost variables in all for each of the } 937 \\
\text { participants, for a total of } 282037 \text { cost elements, of which } 40592(14.4 \%) \text { were missing. } \\
\text { †Housing in which support staff are located within the building; also includes (notably for Toronto) subsidized rooms in buildings without onsite support staff. }\end{array}$} \\
\hline
\end{tabular}

The results of the unadjusted and adjusted regressions are given in Table 3. The dependent variables were total costs, and the 3 most important cost elements overall (other than social assistance or disability benefits) were ambulatory visits, psychiatric hospital stays and justice-related costs (combining police, court appearances and incarcerations). After other factors were controlled for, total costs were lower in Moncton than in the other cities. Costs were associated with only 2 other variables: level of functioning, with an increase of 10 points on the MCAS (indicating a material increase in the level of functioning) that was associated with a decrease in costs of $15 \%$ (odds ratio 0.85 [95\% CI 0.80-0.91]); and having had 2 or more hospital stays for psychiatric causes in 1 of the 5 years before study entry, which was associated with an increase in costs of $35 \%$ (95\% CI 1.21-1.51).

When other factors were controlled for, a history of repeated psychiatric hospital stays was associated with an increase in costs of ambulatory visits of $48 \%$ [OR 1.48] (95\% CI 1.21-1.81) and an increase in the costs of psychiatric hospital stays of $510 \%$ [OR 5.10] (95\% CI 2.51-10.34). Two other variables were associated with the costs of psychiatric hospital stays: alcohol dependence or abuse at baseline was associated with a decrease in costs of $62 \%$ [OR 0.38] (95\% CI 0.19-0.76), and a 10-point increase on the MCAS was associated with a decrease of 44\% [OR 0.56] (95 CI 0.38-0.81). Combined justice-related costs were lower for older people (3\% [OR 0.97] decrease [95\% CI 0.96-0.99] for each additional year of age), 37\% [OR 0.63] lower (95\% CI 0.47 0.84 ) for women, $53 \%$ [OR 1.53] higher (95\% CI 1.15-2.02) for people with alcohol abuse or dependence at baseline, 22\% [OR 0.78 ] lower (95\% CI 0.67-0.92) per additional 10 points on the MCAS and 2.47 times [OR 2.47] higher (95\% CI 1.89-3.23) for people who had been arrested in the 6 months before baseline.

We highlight 1 result from the unadjusted regressions. Although an increase of 1 year in the longest single period of homelessness was not significantly associated with total costs when other factors were controlled for, bivariately it was associated with a $3 \%$ [OR 1.03] increase (95\% CI 1.01-1.05) in total costs. This indicates that, on average, allowing correlated factors to vary at the same time, total costs engendered by people who have been homeless longer tend to be higher.

Finally, the average cost per year of filled prescriptions for the 169/183 Montréal participants for whom we had these 


\begin{tabular}{|c|c|c|c|c|c|c|c|c|}
\hline \multirow[b]{3}{*}{ Variable } & \multicolumn{6}{|c|}{ Cost element ${ }^{*} \dagger$} & & \\
\hline & \multicolumn{2}{|c|}{ Ambulatory visits } & \multicolumn{2}{|c|}{ Psychiatric hospital stays } & \multicolumn{2}{|c|}{ Justice-related servicesł } & \multicolumn{2}{|c|}{ Total } \\
\hline & $\begin{array}{l}\text { Unadjusted } \\
\text { ORß』 } \\
(95 \% \mathrm{Cl})\end{array}$ & $\begin{array}{l}\text { Adjusted } \\
\text { ORß̊ } \\
(95 \% \mathrm{Cl})\end{array}$ & $\begin{array}{l}\text { Unadjusted } \\
\text { ORßी } \\
(95 \% \mathrm{Cl})\end{array}$ & $\begin{array}{l}\text { Adjusted } \\
\text { ORßी } \\
(95 \% \mathrm{Cl})\end{array}$ & $\begin{array}{l}\text { Unadjusted } \\
\text { ORßी } \\
(95 \% \mathrm{Cl})\end{array}$ & $\begin{array}{l}\text { Adjusted } \\
\text { OR§I } \\
(95 \% \mathrm{Cl})\end{array}$ & $\begin{array}{l}\text { Unadjusted } \\
\text { ORßी } \\
(95 \% \mathrm{Cl})\end{array}$ & $\begin{array}{l}\text { Adjusted } \\
\text { OR§ી } \\
(95 \% \mathrm{Cl})\end{array}$ \\
\hline \multicolumn{9}{|l|}{ Site } \\
\hline Montréal v. Moncton & $\begin{array}{c}1.00 \\
(0.68-1.47)\end{array}$ & $\begin{array}{c}0.98 \\
(0.68-1.41)\end{array}$ & $\begin{array}{c}3.75 \\
(1.16-12.09)\end{array}$ & $\begin{array}{c}2.34 \\
(0.63-8.71)\end{array}$ & $\begin{array}{c}1.52 \\
(0.94-2.48)\end{array}$ & $\begin{array}{c}1.28 \\
(0.77-2.13)\end{array}$ & $\begin{array}{c}1.94 \\
(1.56-2.42)\end{array}$ & $\begin{array}{c}1.85 \\
(1.50-2.27\end{array}$ \\
\hline Toronto v. Moncton & $\begin{array}{c}2.12 \\
(1.46-3.10)\end{array}$ & $\begin{array}{c}1.99 \\
(1.38-2.86)\end{array}$ & $\begin{array}{c}2.50 \\
(0.81-7.71)\end{array}$ & $\begin{array}{c}0.93 \\
(0.25-3.42)\end{array}$ & $\begin{array}{c}2.16 \\
(1.35-3.47)\end{array}$ & $\begin{array}{c}1.57 \\
(0.94-2.62)\end{array}$ & $\begin{array}{c}1.94 \\
(1.56-2.40)\end{array}$ & $\begin{array}{c}1.77 \\
(1.44-2.17)\end{array}$ \\
\hline Winnipeg v. Moncton & $\begin{array}{c}1.62 \\
(1.11-2.36)\end{array}$ & $\begin{array}{c}1.61 \\
(1.11-2.32)\end{array}$ & $\begin{array}{c}1.56 \\
(0.48-5.02)\end{array}$ & $\begin{array}{c}1.12 \\
(0.28-4.44)\end{array}$ & $\begin{array}{c}1.61 \\
(0.99-2.61)\end{array}$ & $\begin{array}{c}1.40 \\
(0.82-2.39)\end{array}$ & $\begin{array}{c}1.56 \\
(1.25-1.94)\end{array}$ & $\begin{array}{c}1.60 \\
(1.30-1.98)\end{array}$ \\
\hline Vancouver v. Moncton & $\begin{array}{c}1.37 \\
(0.93-2.01)\end{array}$ & $\begin{array}{c}1.13 \\
(0.78-1.63)\end{array}$ & $\begin{array}{c}4.76 \\
(1.47-15.45)\end{array}$ & $\begin{array}{c}2.77 \\
(0.74-10.44)\end{array}$ & $\begin{array}{c}1.22 \\
(0.75-1.98)\end{array}$ & $\begin{array}{c}0.76 \\
(0.46-1.26)\end{array}$ & $\begin{array}{c}1.85 \\
(1.48-2.31)\end{array}$ & $\begin{array}{c}1.58 \\
(1.28-1.95)\end{array}$ \\
\hline Age & $\begin{array}{c}0.99 \\
(0.98-1.00)\end{array}$ & $\begin{array}{c}1.00 \\
(0.99-1.00)\end{array}$ & $\begin{array}{c}0.99 \\
(0.97-1.02)\end{array}$ & $\begin{array}{c}0.96 \\
(0.93-1.00)\end{array}$ & $\begin{array}{c}0.97 \\
(0.95-0.98)\end{array}$ & $\begin{array}{c}0.97 \\
(0.96-0.99)\end{array}$ & $\begin{array}{c}1.00 \\
(0.99-1.00)\end{array}$ & $\begin{array}{c}1.00 \\
(0.99-1.00)\end{array}$ \\
\hline Female v. male sex & $\begin{array}{c}1.05 \\
(0.84-1.32)\end{array}$ & $\begin{array}{c}1.18 \\
(0.96-1.44)\end{array}$ & $\begin{array}{c}0.93 \\
(0.52-1.65)\end{array}$ & $\begin{array}{c}1.37 \\
(0.63-2.95)\end{array}$ & $\begin{array}{c}0.55 \\
(0.42-0.71)\end{array}$ & $\begin{array}{c}0.63 \\
(0.47-0.84)\end{array}$ & $\begin{array}{c}0.93 \\
(0.83-1.05)\end{array}$ & $\begin{array}{c}1.03 \\
(0.92-1.15)\end{array}$ \\
\hline Psychotic disorder & $\begin{array}{c}1.38 \\
(1.08-1.76)\end{array}$ & $\begin{array}{c}1.05 \\
(0.84-1.33)\end{array}$ & $\begin{array}{c}3.08 \\
(1.57-6.06)\end{array}$ & $\begin{array}{c}2.01 \\
(0.76-5.28)\end{array}$ & $\begin{array}{c}1.39 \\
(1.04-1.87)\end{array}$ & $\begin{array}{c}1.06 \\
(0.77-1.45)\end{array}$ & $\begin{array}{c}1.28 \\
(1.13-1.46)\end{array}$ & $\begin{array}{c}1.04 \\
(0.92-1.18)\end{array}$ \\
\hline $\begin{array}{l}\text { Alcohol dependence or } \\
\text { abuse at baseline }\end{array}$ & $\begin{array}{c}1.34 \\
(1.09-1.66)\end{array}$ & $\begin{array}{c}1.12 \\
(0.92-1.38)\end{array}$ & $\begin{array}{c}0.57 \\
(0.32-1.00)\end{array}$ & $\begin{array}{c}0.38 \\
(0.19-0.76)\end{array}$ & $\begin{array}{c}1.84 \\
(1.42-2.37)\end{array}$ & $\begin{array}{c}1.53 \\
(1.15-2.02)\end{array}$ & $\begin{array}{c}1.09 \\
(0.98-1.22)\end{array}$ & $\begin{array}{c}1.07 \\
(0.96-1.19)\end{array}$ \\
\hline $\begin{array}{l}\text { Illicit drug dependence or } \\
\text { abuse at baseline }\end{array}$ & $\begin{array}{c}1.11 \\
(0.89-1.38)\end{array}$ & $\begin{array}{c}1.05 \\
(0.86-1.29)\end{array}$ & $\begin{array}{c}0.74 \\
(0.43-1.26)\end{array}$ & $\begin{array}{c}0.43 \\
(0.21-0.89)\end{array}$ & $\begin{array}{c}1.89 \\
(1.46-2.44)\end{array}$ & $\begin{array}{c}1.35 \\
(1.02-1.80)\end{array}$ & $\begin{array}{c}1.06 \\
(0.95-1.19)\end{array}$ & $\begin{array}{c}1.00 \\
(0.89-1.12)\end{array}$ \\
\hline $\begin{array}{l}\text { Longest single period of } \\
\text { homelessness in years }\end{array}$ & $\begin{array}{c}1.01 \\
(0.98-1.05)\end{array}$ & $\begin{array}{c}1.00 \\
(0.97-1.02)\end{array}$ & $\begin{array}{c}1.05 \\
(0.98-1.12)\end{array}$ & $\begin{array}{c}1.05 \\
(0.97-1.14)\end{array}$ & $\begin{array}{c}1.06 \\
(1.02-1.10)\end{array}$ & $\begin{array}{c}1.03 \\
(0.99-1.07)\end{array}$ & $\begin{array}{c}1.03 \\
(1.01-1.05)\end{array}$ & $\begin{array}{c}1.01 \\
(1.00-1.03)\end{array}$ \\
\hline $\begin{array}{l}\text { Functioning as measured } \\
\text { by MCAS ( } 10 \text { points) }\end{array}$ & $\begin{array}{c}0.84 \\
(0.74-0.96)\end{array}$ & $\begin{array}{c}0.87 \\
(0.76-0.99)\end{array}$ & $\begin{array}{c}0.41 \\
(0.29-0.58)\end{array}$ & $\begin{array}{c}0.56 \\
(0.38-0.81)\end{array}$ & $\begin{array}{c}0.75 \\
(0.65-0.87)\end{array}$ & $\begin{array}{c}0.78 \\
(0.67-0.92)\end{array}$ & $\begin{array}{c}0.81 \\
(0.76-0.86)\end{array}$ & $\begin{array}{c}0.85 \\
(0.80-0.91\end{array}$ \\
\hline $\begin{array}{l}\geq 2 \text { psychiatric hospital } \\
\text { stays in } 1 \text { of the } 5 \mathrm{yr} \text { before } \\
\text { baseline }\end{array}$ & $\begin{array}{c}1.57 \\
(1.28-1.92)\end{array}$ & $\begin{array}{c}1.48 \\
(1.21-1.81)\end{array}$ & $\begin{array}{c}4.94 \\
(2.83-8.63)\end{array}$ & $\begin{array}{c}5.10 \\
(2.51-10.34)\end{array}$ & $\begin{array}{c}1.20 \\
(0.94-1.54)\end{array}$ & $\begin{array}{c}1.11 \\
(0.85-1.46)\end{array}$ & $\begin{array}{c}1.47 \\
(1.32-1.64)\end{array}$ & $\begin{array}{c}1.35 \\
(1.21-1.51)\end{array}$ \\
\hline $\begin{array}{l}\geq 1 \text { arrests in } 6 \text { mo before } \\
\text { baseline }\end{array}$ & $\begin{array}{c}1.18 \\
(0.95-1.46)\end{array}$ & $\begin{array}{c}1.07 \\
(0.88-1.30)\end{array}$ & $\begin{array}{c}0.81 \\
(0.46-1.43)\end{array}$ & $\begin{array}{c}0.80 \\
(0.35-1.83)\end{array}$ & $\begin{array}{c}2.98 \\
(2.29-3.89)\end{array}$ & $\begin{array}{c}2.47 \\
(1.89-3.23)\end{array}$ & $\begin{array}{c}1.23 \\
(1.09-1.38)\end{array}$ & $\begin{array}{c}1.15 \\
(1.03-1.28)\end{array}$ \\
\hline $\begin{array}{l}\dagger \text { Coefficients with a } p \text { value of } \\
\text { †Includes police, court appear } \\
\text { §Indicates the fraction by whic } \\
\text { |Data were best fit with a log I }\end{array}$ & $\begin{array}{l}\text { ts rise or f } \\
\text { nction and }\end{array}$ & ns. & to 1 , or wher & $\begin{array}{l}\text { ratio. } \\
\text { uding only that } \\
\text { of comparison }\end{array}$ & $\begin{array}{l}\text { iable; in the } \\
\text { and their } 95^{\circ}\end{array}$ & $\begin{array}{l}\text { sted columns, } \\
\text { are bolded. }\end{array}$ & ficients & from a single \\
\hline
\end{tabular}

data was \$3083 (standard deviation \$4057) (median \$1662, range \$0-\$22 826 [interquartile range \$428-\$3910]).

\section{Interpretation}

In this sample of homeless people with mental illness, comprehensive costs per year, excluding medications, ranged from about \$56 000 per year in Canada's 3 largest cities to about $\$ 30000$ per year in Moncton. Data from Montréal indicated that this cost would increase by about $\$ 3000$ if medications were included. Assuming that the cost of medications is similar across cities, the annual costs to society of homeless people with mental illness averaged about \$59000 in Canada's 3 largest cities, about $\$ 49000$ in Winnipeg and about $\$ 33000$ in Moncton. Annual costs were highly variable across partici- pants, ranging from $-\$ 15530$ to $\$ 341535$ when earnings were subtracted from health, social and justice services. Spending on different kinds of services also varied greatly across cities. Of particular note, spending on psychiatric hospital stays was much greater in Vancouver and Montréal than in the 3 other cities, whereas spending on justice-related services (not including incarcerations) was much higher in Toronto than in the other cities. Costs of supportive housing were much higher in Montréal than in the other cities. Among the variables that we had hypothesized might have been associated with higher overall costs, only 2 turned out to be significantly associated with greater overall costs after adjustment for other factors: a lower level of functioning and having had 2 or more psychiatric hospital stays in 1 of the 5 years before study entry. 
Our overall cost estimate is comparable to that previously reported on the basis of a modelling study conducted in Vancouver, over $\$ 63000$ in 2016 dollars. ${ }^{5}$ It is substantially lower than the Calgary estimates of $\$ 72444$ for transiently homeless people and $\$ 134642$ for chronically homeless people. ${ }^{6}$ The difficulty of apportioning many costs such as those of health care services between homeless and housed people may make systems-level estimation of the costs of homelessness per person, as was done in the Calgary study, an especially perilous undertaking.

The At Home/Chez Soi study deliberately chose not to consider previous service use as an inclusion or exclusion criterion, focusing instead on level of need. Some of the very ill participants lived in makeshift shelters and avoided contact with the formal service system as much as possible. A small number were not chronically homeless and earned enough income over the 2 years following study entry to more than offset any costs that they engendered. At the other extreme, $10 \%$ of participants engendered costs in excess of $\$ 93165$, reflecting high use of many services. This indicates that homelessness-reduction strategies can focus interventions on high-cost users, ${ }^{32}$ who present more opportunities for cost savings, or, as in the case of the At Home/Chez Soi project, on people with the highest level of need, who may not be among the highest-cost users. A mixed strategy targeting people who engender very high costs or with a very high level of apparent need, or both, could also be pursued.

Contrary to previous reports, ${ }^{33,34}$ baseline alcohol or drug abuse or dependence did not emerge as predictive of total costs in our study. The overall near-absence of an association with total costs masks 2 opposing associations with components of costs: that alcohol abuse or dependence is associated with an increase in justice-related costs but also with a reduction in psychiatric hospital stays. It may be that people with substance abuse tend to be diverted away from inpatient care toward the criminal justice system.

The fact that level of functioning, as assessed with the MCAS, turned out to be more predictive of costs in multivariate regression than almost any other variable tested is noteworthy. It suggests that it is not so much substance abuse, or homelessness history, or specific mental health conditions per se that predicts costs but, rather, the person's level of functioning. Given that the MCAS score can also be interpreted as an indicator of level of need, this scale could be used efficiently as a tool for need assessment (together with a history of 2 or more psychiatric hospital stays in 1 of the previous 5 years, the other variable that turned out to have a significant impact on overall costs when other factors were controlled for) in service delivery settings. Both these variables had even larger and more highly statistically significant odds ratios in multivariate regression, which confirms their value as stand-alone predictors. This does not, of course, preclude the possibility that another similarly low-cost approach would have greater predictive power still.

It is tempting to use our per-person estimates of the cost of homelessness of mentally ill people to derive an estimate of the total cost of homelessness in Canada. Data on relative numbers of homeless people to which our cost estimates could be assigned would be needed to this end but are not available at present. The annual prevalence of mental illness among homeless people in general is difficult to determine as it depends on who is counted as homeless and how a determination of mental illness is made; estimates vary widely. ${ }^{35,36} \mathrm{~A}$ more accurate way of estimating the costs of homelessness in Canada would require better estimates of the numbers of people belonging to various subgroups (e.g., chronically homeless people in Calgary), obtaining a representative sample of each group, ascertaining the costs over 1 year for each person in each sample and constructing a weighted overall cost estimate; however, that would be a very costly undertaking and, in our view, unnecessary. Per-person estimates such as those derived in the present study indicate that a great many homeless people in Canada each cost the government, and society more broadly, a considerable amount each year. This, together with the egregiously poor quality of life and poor health of so many homeless people, is sufficient to justify the search for the most effective, and most cost-effective, program and policy responses to help those in such situations and prevent others from falling into episodic or chronic homelessness.

\section{Limitations}

This study has several limitations. First, the use of self-reports to measure service use is subject to error. However, we made a partial adjustment, based on Montréal data, for over- and underreporting of visits. Furthermore, there is evidence, including from the present trial, to suggest that, although selfreports may under- or overreport service use, they are fairly reliable. ${ }^{16,37}$ Second, although we expended considerable effort on unit cost estimation, the necessity of making a number of simplifying assumptions in the calculation of unit costs means that these costs necessarily include some error. These 2 limitations notwithstanding, the plausibility of our regression findings, including by cost category, suggests that the costs we have estimated have considerable validity. Third, we had data on the cost of medications for only 1 site, and those costs turned out to be substantial. There may be significant variation in this cost across sites. Fourth, only people with mental illness who were homeless or recently homeless at baseline were included in the sample, which limits the generalizability of our findings. Finally, our cost estimates are influenced by the unit costs estimated for each city. Although this recognizes that, for instance, facilities and staffing offered at emergency shelters tend to vary across cities, it may also suggest differences in intensity of services that are actually the result of differences in unit costs.

\section{Conclusion}

Our study confirms, on the basis of a much larger sample and much more detailed data than have been gathered in the past, that homeless people with mental illness engender, on average, very high economic costs for society, from high use of health, social and justice services combined with income received from governmental benefits. Furthermore, patterns of resource allocation varied greatly from city to city. These findings, together with the low quality of life and health problems of homeless people, suggest the need for a comprehen- 
sive response to homelessness and opportunities for moreeffective allocation of resources within existing budgets. With this goal in view, plans to end homelessness include community mental health responses such as Housing First that offset some of these costs as well as interventions to prevent people from becoming homeless in the first place.

\section{References}

1. Gaetz S, Dej E, Richter T, et al. The state of homelessness in Canada 2016. Toronto: Canadian Observatory on Homelessness Press; 2016.

2. A plan, not a dream: how to end homelessness in 10 years. Calgary: Canadian Alliance to End Homelessness; 2012.

3. Tsemberis S. Housing First: the Patbways model to end homelessness for people with mental illness and addiction. Center City (MN): Hazelden Publishing; 2010.

4. Eberle M, Kraus D, Pomeroy S, et al. Homelessness - causes \& effects: the costs of homelessness in British Columbia. Vol. 3. Vancouver: British Columbia Ministry of Social Development and Economic Security and BC Housing Management Commission; 2001

5. Patterson M, Somers J, McIntosh K, et al. Housing and support for adults with severe addictions and/or mental illness in British Columbia. Vancouver: Centre for Applied Research in Mental Health and Addiction, Faculty of Health Sciences, Simon Fraser University; 2007.

6. Calgary Homeless Foundation. Report on the cost of homelessness in the city of Calgary. Toronto: RSM Richter \& Associates; 2008.

7. Table 326-0020: Consumer Price Index, monthly $(2002=100$ unless otherwise noted) [CANSIM (database)]. Ottawa: Statistics Canada; 2016. Available: www5.statcan.gc.ca/cansim/a26? lang=eng\&retrLang=eng\&id $=3260020 \& \&$ pattern $=\&$ stByVal $=1 \& \mathrm{p} 1=1 \& \mathrm{p} 2=37 \&$ tabMode=data Table $\&$ csid=\#customize Tab (accessed 2016 Nov. 17).

8. Goering PN, Streiner DL, Adair C, et al. The At Home/Chez Soi trial protocol: a pragmatic, multi-site, randomised controlled trial of a Housing First intervention for homeless individuals with mental illness in five Canadian cities. BM7 Open 2011:1:e000323.

9. Stergiopoulos V, Hwang SW, Gozdzik A, et al. Effect of scattered-site housing using rent supplements and intensive case management on housing stability among homeless adults with mental illness: a randomized trial. $7 A M A 2015$; 313:905-15.

10. Aubry T, Goering P, Veldhuizen S, et al. A multiple-city RCT of housing first with assertive community treatment for homeless Canadians with serious mental illness. Psychiatr Serv 2016;67:275-81.

11. Veldhuizen S, Adair CE, Méthot C, et al. Patterns and predictors of attrition in a trial of a housing intervention for homeless people with mental illness. Soc Psychiatry Psychiatr Epidemiol 2015;50:195-202.

12. Barker S, Barron N, McFarlane BH, et al. A community ability scale for chronically mentally ill consumers: Part I. Reliability and validity. Community Ment Health 7 1994:30:363-83.

13. Dickerson FB, Origoni AE, Pater A, et al. An expanded version of the Multnomah Community Ability Scale: anchors and interview probes for the assessment of adults with serious mental illness. Community Ment Health 7 2003;39: $131-7$.

14. Tsemberis S, McHugo G, Williams V, et al. Measuring homelessness and residential stability: the Residential Time-Line Follow-Back Inventory. 7 Coтmunity Psychol 2007;35:29-42

15. Latimer EA, Lecomte T, Becker DR, et al. Generalisability of the individual placement and support model of supported employment: results of a Canadian randomised controlled trial [published erratum in Br 7 Psychiatry 2006;189: 191]. Br 7 Psychiatry 2006;189:65-73

16. Somers JM, Moniruzzaman A, Currie L, et al. Accuracy of reported service use in a cohort of people who are chronically homeless and seriously mentally ill. BMC Psychiatry 2016;16:41.

17. Drummond MF, Sculpher MJ, Claxton K, et al. Methods for the economic evaluation of health care programmes. 4th ed. Oxford (UK): Oxford University Press; 2015 .

18. Weisbrod BA, Test MA, Stein LI. Alternative to mental hospital treatment. II. Economic benefit-cost analysis. Arch Gen Psychiatry 1980;37:400-5.

19. Meltzer D. Accounting for future costs in medical cost-effectiveness analysis. $\mathcal{F}$ Health Econ 1997;16:33-64.

20. Meltzer D. Future costs in medical cost-effectiveness analysis. In: Jones AM, editor. The Elgar companion to bealth economics. Cheltenham (UK): Edward Elgar Publishing; 2012.

21. Salkever D. Social costs of expanding access to evidence-based supported employment: concepts and interpretive review of evidence. Psychiatr Serv 2013; 64:111-9.

22. Cannon NL, McGuire T, Dickey B. Capital costs in economic program evaluation: the case of mental health services. In: Catteral JS, editor. New directions for program evaluation: economic evaluation of public programs. No. 26. San Francisco: Jossey-Bass; 1995:69-82.
23. Hwang SW, Weaver J, Aubry T, et al. Hospitalization costs associated with homelessness in Canada. Med Care 2011;49:350-4.

24. Poremski D, Distasio J, Hwang SW, et al. Employment and income of people who experience mental illness and homelessness in a large Canadian sample. Can f Psychiatry 2015;60:379-85.

25. Shao J, Sitter RR. Bootstrap for imputed survey data. 7 Am Stat Assoc 1996;91: $1278-88$.

26. Azur MJ, Stuart EA, Frangakis C, et al. Multiple imputation by chained equations: What is it and how does it work? Int 7 Methods Psychiatr Res 2011;20:40-9.

27. Barber J, Thompson S. Multiple regression of cost data: use of generalized linear models. 7 Health Serv Res Policy 2004;9:197-204.

28. Mitchell MS, Léon CLK, Byrne TH, et al. Cost of health care utilization among homeless frequent emergency department users. Psychol Serv 2017;14:193-202.

29. West S, Patterson D, Mastronardi A, et al. Individual predictors of community costs before and after Housing First. 7 Poverty 2014;18:231-53.

30. Pregibon D. Goodness of link tests for generalized linear models. Appl Stat 1980;29:15-24.

31. Manning WG, Mullahy J. Estimating log models: To transform or not to transform? 7 Health Econ 2001;20:461-94.

32. Larimer ME, Malone DK, Garner MD, et al. Health care and public service use and costs before and after provision of housing for chronically homeless persons with severe alcohol problems. FAMA 2009;301:1349-57.

33. Dickey B, Azeni H. Persons with dual diagnoses of substance abuse and major mental illness: their excess costs of psychiatric care. Am 7 Public Health 1996;86: 973-7.

34. Bartels SJ, Teague GB, Drake RE, et al. Substance abuse in schizophrenia: service utilization and costs. 7 Nerv Ment Dis 1993;181:227-32.

35. Fazel S, Khosla V, Doll H, et al. The prevalence of mental disorders among the homeless in Western countries: systematic review and meta-regression analysis. PLoS Med 2008; 5:e225.

36. Khandor E, Mason K, Hwang SW, et al. The Street Health Report 2007. Toronto: Street Health; 2007.

37. Bhandari A, Wagner T. Self-reported utilization of health care services: improving measurement and accuracy. Med Care Res Rev 2006;63:217-35.

Affiliations: Department of Psychiatry (Latimer), McGill University; Douglas Mental Health University Institute (Latimer, Rabouin, Cao, Ly, Powell), West Island Integrated University Health and Social Services Centre, Montréal, Que.; Centre for Research on Educational and Community Services and School of Psychology (Aubry), University of Ottawa, Ottawa, Ont.; Department of Geography (Distasio), University of Winnipeg, Winnipeg, Man.; Division of General Internal Medicine (Hwang), Department of Medicine, University of Toronto; Centre for Urban Health Solutions (Hwang), Li Ka Shing Knowledge Institute, St. Michael's Hospital, Toronto, Ont.; Department of Psychiatry (Somers), Simon Fraser University, Burnaby, BC; Department of Psychiatry (Stergiopoulos), University of Toronto, Toronto, Ont.; McMaster University (Veldhuizen), Hamilton, Ont.; Department of Epidemiology and Biostatistics (Moodie), McGill University; Centre de recherche de l'Institut universitaire en santé mentale de Montréal and Department of Psychiatry (Lesage), Université de Montréal, Montréal, Que.; Centre for Addiction and Mental Health (Stergiopoulos, Goering [deceased]) and Department of Psychiatry (Goering), University of Toronto, Toronto, Ont.

Contributors: All of the authors contributed substantially to the conception and design, acquisition of data, or analysis and interpretation of data. Eric Latimer drafted the manuscript, and the remaining authors revised it critically for important intellectual content. All of the authors approved the final version to be published and agreed to act as guarantors of the work.

Funding: This research was made possible through a financial contribution from Health Canada to the Mental Health Commission of Canada. The Mental Health Commission of Canada oversaw the design and conduct of the study. The study's International Standard Randomised Control Trial Number register identifier is ISRCTN42520374. The views expressed herein solely represent those of the authors.

Acknowledgements: The authors thank Jayne Barker and Cameron Keller, the At Home/Chez Soi national research team, the research teams and coordinators at the 5 sites, the service and housing providers and the people with lived experience, who have contributed to this project and the research. The late Paula Goering was the lead investigator of the At Home/Chez Soi project.

Supplemental information: For reviewer comments and the original submission of this manuscript, please see www.cmajopen.ca/content/5/3/ E576/suppl/DC1. 